\title{
Contractility of lungs and air-tubes: experiments performed in 1840 by Charles J.B. Williams
}

\author{
J. Lötvall
}

\begin{abstract}
Contractility of lungs and air-tubes: experiments performed in 1840 by Charles J.B.
\end{abstract} Williams. J. Lötvall. CERS Journals Ltd 1994.

ABSTRACT: In the 18th century, some medical practitioners considered the main pathological feature of asthma to be the production of mucus. Later, during the 19th century, airway smooth muscle contraction was recognized to be a possible cause of airflow obstruction. However, not until 1840 was the contractility of airway smooth muscle clearly established by Charles J.B. Williams, a famous London physician.

In a number of innovative experiments in dogs, rabbits, livestock and even donkeys, he showed: 1) that airways contract in response to electrical stimulation; 2) that the observed contractions are almost totally abolished by belladonna and stramonium (anticholinergics); 3) that the responses faded over time; and 4) that morphine inhibited the observed responses. Application of irritant fluids into the tracheal lumen produced similar responses.

These interesting observations made by Williams will be reviewed, and related to current theories concerning modulation of airway smooth muscle responsiveness. Eur Respir J., 1994, 7, 592-595.
Division of Clinical Pharmacology, Sahlgren's
University Hospital, University of Göteborg, Gothenburg, Sweden.

Division of Clinical Pharmacology (Department of Pharmacology) Sahlgren's University Hospital University of Göteborg S-413 45 Gothenburg Sweden

Keywords: Asthma airways

nerves

Received: October 91992

Accepted after revision October 31993
Since the time of SALTER [1], airway smooth muscle contraction has been considered to be one of the most important contributors to the obstructive symptoms of asthma, whereas mucus production was considered to be an important cause of asthma by some earlier medical practitioners [2]. During the first half of the 19th century, however, it was known that the bronchial walls contain muscular elements, but the capacity of these muscles to contract was not well established [3, 4]. This question was, therefore, experimentally approached by Charles J.B. Williams in the summer of 1840 , for which purpose he had been engaged by the British Association for the Advancement of Science [3, 4]. The results were published both in the reports of the Association [3], and in the fourth edition of a book on diseases of the chest by Williams [4]. As it turned out, these exciting original experiments, performed at University College, London, established some important regulatory mechanisms in the airways that are still being investigated in laboratories all over the world.

\section{Charles J.B. Williams}

Charles J.B. Williams (1805-1889) was a prominent 19th century London physician, with a great interest in the pathophysiology of asthma. Son of a clergyman, Williams studied medicine in Edinburgh, starting in 1820 , and received his M.D. thesis in 1824. After a brief period in London in 1824-1825, Williams pursued his clinical career by spending one year in Paris, studying mainly with Laënnec [5, 6]. Williams was considered to be one of the most eminent lung physicians in mid19 th century London. As early as 1835 , Williams was elected Fellow of the Royal Society, after being introduced by Faraday. However, the election of Williams was not without opposition, and, as it turned out, his contribution to the Society has been very small. One reason, mentioned by Williams in his memoirs, was that he was disappointed when the first paper that he submitted to the Society was refused, and was therefore deterred from offering any other papers in the future. Later in life, Williams strongly criticized the procedure of the election of Fellows, an opinion that may have further decreased Williams' contributions to the Society. Instead, he preferred the younger British Association for the Advancement of Science.

In 1839, Williams was elected Professor of Medicine at University College, London, and in 1840 he became Fellow of the Royal College of Physicians. Williams made a large contribution to the early development of pulmonary medicine, and took an active part in founding the Brompton Hospital in Chelsea, together with Philip Rose (later Sir) [7]. Williams became the first president of both the Pathological Society (1846) and the New Sydenham Society (1858).

Williams contributed to the education of medicine with two major textbooks. "A Rational Exposition of the 
Physical Signs of Diseases of the Chest", was published as early as 1830 , only 10 yrs after he started his medical studies in Edinburgh. Further volumes were published in 1833,1835 , and 1840 , and the title was changed with the third edition to the more ambitious "The Pathology and Diagnosis of Diseases of the Chest; a Rational Exposition of their Physical Signs". In 1843, the first of three editions of "Principles of Medicine" was published, a popular and very successful standard textbook. Williams also accumulated a large amount of material on diseases of the chest, and started to work on a textbook on this subject, together with Richard Quain, but unfortunately, this comprehensive work, never appeared in published form.

When reading Williams memoirs and articles about him, one receives the impression that he was an extremely knowledgeable and thorough physician, and very highly regarded by his colleagues and patients. However, he also seems to have been quite provocative and radical, as evidenced from the various controversies in which he was engaged from time to time. His criticism of the Royal Society, has been mentioned previously, but he also argued strongly for reforms of the Royal College of Physicians, which aroused powerful emotions among many of his contemporary colleagues. The antagonism against him may be illustrated by the fact that the pages containing his obituary (Lancet 1889 issue) have been removed from the edition in the Royal College Library, perhaps by someone opposed to his ideas. He also had a famous controversy with Hope, with regard to the originality of certain experiments on the sounds of the heart, and with other colleagues on the diagnosis of the illness of the famous surgeon, Liston. All these controversies attracted great attention at the time, and may to some degree illustrate Williams' personality.

Not only was Williams an extraordinary physician and prominent person in 19th century England, but he was also one of the greatest early researchers in the field of respiratory medicine. Possibly, one of his most important contributions to basic respiratory science at the time are his observations concerning the contractility and modulation of tracheobronchial smooth muscle. In fact, some of his observations have been rediscovered in recent years, and their important role in airway physiology is now becoming well-established.

\section{Methodology}

In his report to the British Association for the Advancement of Science, Williams described the methods he used to study the contractility of airway musculature [3, 4]. Most experiments were performed on lungs removed from dogs, killed by pithing, a blow to the head, bleeding or injection of various substances such as morphine, stramonium or belladonna (active ingredient of which is atropine). The lungs were in most instances taken out, together with a portion of the trachea, which was connected to a manometer filled with coloured liquid. In a few experiments, the lungs were left in the body of the animal while stimulated. The trachea and/or lungs were then exposed to various stimuli, including galvanic current (thirty three inch plates) and irritant liquids. The response was measured by observing the manometer and measuring the rise of the liquid in inches and tenths. Irritant liquids were delivered to the airway lumen, through the manometer, or applied directly to the bronchial lumen when the lungs had been opened. The irritants used were diluted ammonia and strong salt solutions.

In Williams' publications, he presents the source of all materials used, as we do today. All extracts used were obtained from Squire, Chemist to H.M. the Queen. However, references to previous scientific literature are not given with the same care.

\section{Contraction of tracheobronchial muscle}

On applying an electric current over the trachea and lungs, Williams found that a prompt increase in the airway luminal pressure was induced, observed as a rise of the liquid in the manometer connected to the trachea. "On passing a galvanic current, from a trough of thirty three-inch plates, from the margin of the lungs to the brass tube in the trachea, the fluid rose quickly, but gradually ...". This experiment was repeated in eight dogs of various sizes, with similar results, and the rise of the fluid column caused by galvanizing the whole lung amounted to 1.5 to 2.5 inches.

In some instances, parts of bronchi or trachea were removed from the lungs, opened longitudinally, and exposed to the galvanic instruments. When this was done, a contraction of the membraneous part of the airway wall was observed. Furthermore, the diameters of exposed bronchi were measured during galvanic stimulation, which produced clear narrowing, sometimes to half, and in some instances to less than half their former diameters.

With these basic experiments, the contractility of the tracheobronchial tree was firmly established. As has been proved since, the contractions induced by electrical stimulation over airway smooth muscle are usually induced by activation of nerves, as tetrodotoxin (TTX), a specific nerve toxin, inhibits nerve-induced contractile responses [8]. However, Williams found it difficult to induce contraction of the airways by direct stimulation of the vagi. In one experiment, leaving the lung in the body, no effect was seen when one vagus was pinched or, subsequently, when a galvanic current was applied over the other vagus. However, a small rise of the liquid in the manometer was found "when the nerve was separated and the galvanism was passed through it to the base of one lung". This lack of responsiveness to vagal nerve stimulation may be explained by the type of stimulation used, although it is not clear exactly how Williams was stimulating the tissues electrically. It seems that a direct current galvanometer was used, although the stimulator was not described in detail in the publications. In modern studies of airway nerves, alternate current is used for repeated stimulation, whereas direct current may act directly on smooth muscle cells and may also damage tissues, such as the vagal nerves in the experiment just 
mentioned. It is possible that some of Williams' observations were due to direct effects on non-neural tissues, although there is indirect evidence of an activation of cholinergic nerves in these historical experiments.

\section{Cholinergic mechanisms}

In experiments evaluating the effects of belladonna and stramonium, both potent antimuscarinic compounds, an inhibitory effect of the muscle shortening induced by electrical stimulation was observed. Dogs or rabbits were killed with extracts of belladonna or stramonium injected into the jugular vein or neck tissue. When the lungs had been removed "galvanism produced no effect for several minutes, and then a scarcely perceptible rise". Thus, a major proportion of the observed contractile responses was due to the release of acetylcholine from airway cholinergic nerves. The nature of the remaining small responses observed by Williams are not clear, and could be due to tissue damage, or perhaps, more excitingly, to non-cholinergic mechanisms, for example the release of tachykinins [9].

To Williams, the potent inhibitory effects on "air-tube contractility" of stramonium and belladonna explained their efficacy in asthma. Stramonium was introduced from India in the first years of the 19th century [1, 10], and was considered by contemporary authorities on lung diseases to be a superior remedy for the treatment of spasmodic asthma [1, 3-5]. Williams believed that the superior efficacy of stramonium and belladonna in spasmodic asthma was due to a general inhibitory effect of these drugs on the bronchial muscles. We have since recognized that the inhibitory effects of these compounds are localized to muscarinic receptors; receptors on airway smooth muscle and glands that are activated upon release of acetylcholine from cholinergic vagal fibres.

\section{Fading of responses}

When the contractility of the bronchial muscle had been established, one of the first observations that Williams made was that prolonged electrical stimulation led to fading of the response. He wrote: "the fluid rose quickly, ... but fell slowly when the contact was continued for some seconds ... The rise was repeatedly produced, but to a diminishing extent, and after two or three minutes the effect seemed to be exhausted". A fading similar to the type observed by Williams has been extensively studied in recent years, and is currently believed to be due to inhibitory factors released from airway epithelium. Thus, a fading of nerve-induced contractions of tracheobronchial muscle, similar to that observed by Williams, is seen only in the presence of airway epithelium [11]. The inhibitory substances produced by the epithelial cells are now believed to be both prostaglandin $\mathrm{E}_{2}\left(\mathrm{PGE}_{2}\right)$ and possibly non-prostanoid factors [11-13]. Epithelial damage may eliminate the production of inhibitory factors from the epithelium, which may be one important underlying mechanism of nonspecific bronchial hyper- responsiveness in asthma [13]. However, it should be emphasized that the fading of the responses in Williams' experiments could be due to tissue damage and the release of toxic substances upon the crude electric stimulation.

\section{Inhibition by morphine}

It has recently been shown that cholinergic nerveinduced contraction of guinea-pig trachea is inhibited by opioids, a mechanism that has been suggested to be localized to the nerves prejunctionally [14]. However, similar observations were made by Williams in his early experiments. He found that when a dog was injected with a high dose of an extract of opium before the lungs were removed, the galvanic current "only raised the dynameter slightly, not more than a tenth ... much less than in other cases". Opioids were, at that time, sometimes used in the treatment of asthma, and any beneficial effect may in some cases be explained by the inhibition of airway nerves, an effect that was originally discovered by Williams in 1840 .

\section{Exposure to irritants}

The capacity of irritant gases to induce obstructive symptoms in patients with asthma were well known to Williams. To study this observation in his experimental system, Williams poured the irritating fluid into the lumen of the trachea through the manometer, and observed small responses, which he considered were produced by the irritating liquid. However, "viscid froth" was also collected in the bronchi by these irritants, which Williams believed had impeded the observed responses in the manometer.

To study bronchial responsiveness today, we often give inhaled irritants, such as ozone, $\mathrm{SO}_{2}$, sodium metabisulphite, or hypertonic solutions, to asthmatic patients [15]. The observation made by Williams that saturated salt solutions contract airway smooth muscle, may have been the first finding of bronchoconstriction to a hypertonic solution.

\section{Conclusions}

Charles Williams effectively summarized his experiments: "I trust that many of the results of the preceding experiments are sufficiently evident without further comment. Almost all of them prove that the air-tubes are endowed with irritable contractility, excitable by electric, chemical, and mechanical stimuli, and they possess also tonic contractility. The contractility is manifest in all portions of the air-tubes. In the trachea and larger bronchi it is antagonised by the elasticity of the cartilaginous rings. It does not appear to exist in the vesicular terminations of the air-tubes ... The irritability of the bronchial muscles is soon exhausted by the action of a stimulus, and may in some degree be restored by rest, even when the lung is removed from the body 
for an hour or more. But when the stimulation is long continued, as by intense irritation of the mucous membrane during life, the irritability is not restored by rest, and the tonic contractility is also impaired ... Several vegetable poisons impair or destroy this contractility. Extracts of stramonium and belladonna produced this effect most completely ... morphia also impair this property considerably ...".

In his memoirs, Williams states: "In animals ... poisoned by belladonna or stramonium, this contractility of the tubes was almost destroyed, giving no signs of movement under galvanism. In animals poisoned by opium and by strychnia, it was impaired, but not destroyed; confirming the fact, well known to the experienced practitioner, that these are inferior to belladonna and stramonium as remedies for the spasm of asthma".

These experiments, performed by Williams, are obviously important hallmarks of science, clearly showing that the muscle of the airway wall can contract upon electrical stimulation (most likely nerve-induced effects). Although not aware of the importance of nerves in the observed responses, Williams found that the airway contractility was almost abolished by anticholinergics (thus mediated via the activation of cholinergic nerves; [16]). $\mathrm{He}$ also discovered the fading over time of responses induced by galvanic current, effects that have recently been shown to be due to inhibitory factors released from the airway epithelium [11-13].

Furthermore, application into the airways of irritants, such as saturated salt solutions, were found to produce frothy viscid mucus, as well as contraction of bronchial muscle. Lastly, Williams established an inhibitory effect of opioids in the airways, which has recently been localized to airway nerves [14].

Charles J.B. Williams, being well before his time, deserves to be remembered as one of the most important contributors to our current knowledge of airway pathophysiology.

Acknowledgements: The author would like to thank the librarians of the National Heart and Lung Institute in London, especially L. Dorrington, and the librarians of the Royal College of Physicians in London, for assistance in finding rare references.

\section{References}

1. Salter HH. On asthma: its pathology and treatment. 2nd Edn, London, Churchill, 1868.
2. Bree R. A practical inquiry into disordered respiration; distinguishing the species of convulsive asthma, their causes and indications of cure. 4th Edn, London, Phillips, 1807.

3. Williams CJB. Report of experiments on the physiology of the lungs and air-tubes. Report of the British Association of the Advancement of Science. 1840a, 411-420.

4. Williams CJB. Pathology and diagnosis of diseases of the chest, comprising a rational exposition of their physical signs. London, Churchill, 1840; pp. 320331.

5. Williams CJB. Memoirs of life and work. London, Smith, Elder \& Co, 1884.

6. Obituary in The Lancet. Charles JB Williams, M.D., F.R.S., F.R.C.P., Physician Extraordinary to her Majesty the Queen. Lancet 1889; i: 711-712.

7. Bishop PJ, Lucas BDB, Lucas BGB. The seven ages of the Brompton: a saga of a hospital. London, Seven Corners Press Ltd, 1991.

8. Rogart R. Sodium channels in nerve and muscle membrane. Ann Rev Physiol 1981; 43: 711-725.

9. Lundberg JM, Saria A. Bronchial smooth muscle contraction induced by stimulation of capsaicin-sensitive sensory neurons. Acta Physiol Scand 1982; 116: 473476.

10. Monthly Magazine. On the datura stramonium or thornapple. London, Lewis, 1811.

11. Ullman A, Ciabattoni G, Löfdahl C-G, Svedmyr N, Skoogh B-E. Epithelial $\mathrm{PGE}_{2}$ inhibits the contractile response to cholinergic stimulation in ferret trachea. Pulm Pharmacol 1990; 3: 155-160.

12. Flavahan NA, Aarhus LL, Rimele TJ, Vanhoutte PM. The respiratory epithelium inhibits bronchial smooth muscle tone. J Appl Physiol 1985; 58: 834-838.

13. Busk MF, Vanhoutte PM. Epithelium-dependent responses in airways. In: Kaliner MA, Barnes PJ, Persson CGA, eds. Asthma, its pathology and treatment. New York, Marcel Dekker, 1991; pp. 51-72.

14. Belvisi MG, Stretton CD, Barnes PJ. Modulation of cholinergic neurotransmission in guinea-pig airways by opioids. Br J Pharmacol 1990; 100: 131-137.

15. Cockcroft DW, Hargreave FE. Airway hyperresponsiveness: definition, measurement, and clinical relevance. In: Kaliner MA, Barnes PJ, Persson CGA, eds. Asthma, its Pathology and Treatment. New York, Marcel Dekker, 1991; pp. 51-72.

16. Widdicombe JG, Karlsson J-A, Barnes PJ. Cholinergic mechanisms in bronchial hyperresponsiveness and asthma. In: Kaliner MA, Barnes PJ, Persson CGA, eds. Asthma, its pathology and treatment. New York, Marcel Dekker, 1991; pp. 327-356. 